Original Article (short paper)

\title{
Hyperproteic supplementation attenuates muscle damage after simulated Olympic cross-country mountain biking competition: a randomized case-control study
}

\author{
Alex Sandro Seccato ${ }^{1}$, Fabio dal Bello ${ }^{2}$, Andreia Cristiane Carrenho Queiroz ${ }^{1}$, João Carlos Bouzas

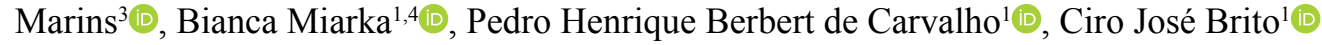 \\ ${ }^{1}$ Universidade Federal de Juiz de Fora, UFJF, Juiz de Fora, MG, Brazil; ${ }^{2}$ Programa de Magister en \\ Ciéncias de la Actividad Física y del Deporte, Facultad de Salud, Universidad Santo Tomás, Santiago, \\ Chile; ${ }^{3}$ Universidade Federal de Viçosa, UFV, Viçosa, MG, Brazil; ${ }^{4}$ Programa de Pós-graduação em \\ Educação Física, Escola de Educação Física e Desportos, Universidade Federal do Rio de Janeiro
}

\begin{abstract}
Aim: We investigated the effect of high-protein (HI-PRO - 70\% protein and 30\% carbohydrate) and highcarbohydrate supplementation ( $\mathrm{HI}-\mathrm{CHO}-70 \%$ carbohydrate and $30 \%$ protein) on muscle damage, haemoglobin, immune response, perceived pain and recovery post-simulated XCO. Methods: For this, 10 amateur athletes (38 \pm 9.6 yrs.) were measured pre-, post- and 24-h post-trial. Results: In comparison to the pre-trial, the post-trial athletes presented leucocytosis $\left(p \leq 0.001 ; 14.7 \pm 6.1\right.$ and $13.6 \pm 5.6$ cells $\times 10^{3}$; for HI-PRO and HI-CHO, respectively) and neutropenia $(p \leq 0.001 ; 11.9 \pm 5.2$ and $10.7 \pm 4.9$ cells $\times 10^{3}$; for HI-PRO and HI-CHO, respectively) but recovered at 24-h post-trial (Leukocytes: $6.9 \pm 1.4$ and 7.1 \pm 1.4 cells $\times 10^{3}$; for HI-PRO and HI-CHO, respectively; neutrophils: $3.6 \pm 1.2$ and $3.9 \pm 1.1$ cells $\mathrm{x} 103$; for HI-PRO and HI-CHO, respectively) without a difference between conditions ( $p=0.808$ and $p=0.531$; for leukocytes and neutrophils, respectively). A similar result was observed for perceived pain and recovery, where the condition did not interfere with these variables between the o measurement moments ( $p=0.245$ and $p=0.491$; for pain and recovery respectively). There was an interaction effect for lactate dehydrogenase (LDH), where HI-PRO presented a lower serum concentration 24-h post-trial compared to HI-CHO ( $p=0.039 ; 181.3 \pm 21.9$ and $201.0 \pm 10.4 \mathrm{IU} / \mathrm{L}$; for HI-PRO and HI-CHO, respectively). Conclusion: HI-PRO supplementation results in better muscle damage recovery but only for LDH. Athletes should evaluate the cost-benefit of choosing the nutrients to be consumed immediately post-training or competition.
\end{abstract}

Keywords: mountain biking; whey-protein; carbohydrate; supplementation; recovery.

\section{Introduction}

Among cycling sports, Olympic cross-country mountain biking (XCO) requires greater physical fitness ${ }^{1}$. The physical demand of XCO has been confirmed by its vigorous intensity, with high anaerobic and aerobic demands ( $>80 \%$ of the tests present values above the lactate threshold and $\sim 90 \%$ of maximal heart rate $)^{2}$. In mountain bike races, post-competition demonstrates an increase in delay onset muscle soreness, perceived pain and high muscle protein (PRO) breakdown, decreasing the muscle strength and physical performance ${ }^{3}$, whereas untrained subjects may present increased muscle damage 72 hours after an exhaustive effort ${ }^{4}$. In this sense, nutritional strategies are elaborated to reduce the adverse effects of the strenuous effort, accelerating the muscle PRO turnover ${ }^{3,5,6}$.

Some studies have shown that certain nutrients accelerate muscle recovery, such as carbohydrates $(\mathrm{CHO})^{5}$, amino acids ${ }^{7}$, whey-protein $^{5}$, and creatine ${ }^{8}$. Cooke, Rybalka, Stathis, Cribb and Hayes ${ }^{5}$ observed that the whey-protein intake preserves the isometric and isokinetic strength after eccentric exercise when compared to CHO. Matsumoto, Koba, Hamada, Sakurai,
Higuchi and Miyata ${ }^{7}$ found that branched-chain amino acid supplementation results in a lower perceived muscle pain, fatigue, and muscle damage. Similar results were observed by $\mathrm{Ra}$, Miyaza, et al. ${ }^{9}$ after an exercise protocol for induced muscle damage. In Mountain Bike athletes measured in an eight-day competition, Cathcart, Murgatroyd, McNab, Whyte and Easton ${ }^{3}$ observed that the intake of a shake containing $80 \%$ of PRO and $20 \%$ of CHO results in better competitive performance and prevents muscle mass loss; however, there was no difference in comparison with the placebo for the muscle damage.

Creatine phosphokinase (CPK) and lactate dehydrogenase (LDH) are widely investigated enzymes for estimating muscle damage ${ }^{10}$. The increase in serum CPK after exercise is directly related to the delay onset muscle soreness ${ }^{4,10}$ and increases the synthesis of cartilage injury markers ${ }^{11}$. In addition, the increased serum CPK concentrations are inversely proportional to the muscle's capacity to produce strength performance post-exercise ${ }^{12}$. LDH is highly concentrated in the skeletal muscle, as this enzyme promotes the conversion of pyruvate to lactate. The association of this serum LDH with muscle damage is closely linked to the increase in serum $\mathrm{CPK}^{13}$. Adequate 
PRO and CHO intakes are essential for maintaining immune function in athletes and to avoid overtraining ${ }^{14,15}$, but post-training supplementation was poorly investigated and the results are contradictory. Hansen, Bangsbo, Jensen, Bibby and Madsen ${ }^{16}$ observed a better recovery response in runners that consumed a shake containing PRO and CHO, but with no effect on immunity. Moreover, Flakoll, Judy, Flinn, Carr and Flinn ${ }^{17}$ found a lower incidence of infections in soldiers who consumed PRO after strenuous exercise against $\mathrm{CHO}$ consumption.

Due to the strenuous physical effort associated with the XCO competition ${ }^{1}$, deleterious effects of training may occur in athletes of this cycling sport, especially in amateurs. Ortega, Ruiz, Gutierrez and Castillo ${ }^{18}$ observed subclinical myocardial injury in amateur competitors $(95 \mathrm{~km}, 2340$ meters altitude accumulated). However, muscle damage can be minimized with correct nutritional replacement strategies ${ }^{3}$. When such procedures are adopted, muscle repair is accelerated; however, an inadequate or non-existent post-training nutrition plan will affect the quality of the next training ${ }^{19}$, leaving the athlete unprepared to compete. In this sense, adequate nutrient intake becomes essential for improving physical performance and achieving sports goals. However, to the best of our knowledge, no studies have compared different proportions of PRO and $\mathrm{CHO}$ and post-XCO competition. Therefore, this study aimed to investigate the influence of two supplementation protocols, namely High protein (HI-PRO) and High carbohydrate (HI-CHO) shakes, after simulated XCO competition on the serum CPK, LDH, and leukocytes, as well as perceived muscle pain and recovery. We hypothesized that nutritional strategies result in different responses to the measured variables.

\section{Methods}

\section{Study design}

This is a cross-sectional randomized double-blind crossover study, where the athletes underwent two trials of XCO simulations on the same track. In the first trial, half of the participants were randomly assigned to the HI-PRO and the others to the HI-CHO condition. The conditions were reversed in the second trial (after $72 \mathrm{hr}$ first trial). The trials followed the rules for $\mathrm{XCO}^{20}$, so a regulation XCO track (regulated by the State cycling federation) was used. According to the Olympic rules, the track is composed of a circuit $(\approx 6 \mathrm{~km})$, where each athlete performed 6 laps. Temperature and humidity were monitored by a digital thermo hygrometer (Gesa 810-190, Gesa ${ }^{\circledR}$, Urduliz, Spain). The performance during the trials was monitored by heart rate (Polar S810i 4SW; Polar ${ }^{\circledR}$, Finland), 1-10 scale for rating of perceived exertion $^{21}$, and total trial time (a digital timer, Kikos ${ }^{\circledR}$, Brazil). Participants were instructed to hydrate ad libitum during the trials. This protocol was approved by the Research Ethics Committee of the University in which it was performed (0330.0.107.000-15).

\section{Participants}

We initially contacted XCO athletes in the city where the data was collected. After our pilot study $(n=4)$, as well as according to specific literature ${ }^{3,5,7}$ we estimated a minimal sample size based on the CPK, LDH and leukocyte response. In order to achieve $80 \%$ statistical power, we calculated a minimum sample of 9 subjects to reach a decrease in 50 I.U./L (CPK and LDH) and 0.2 cells X 103 (leukocytes) when comparing the HI-PRO and HI-CHO conditions (5.2 Granmo, IMIM, Barcelona, Spain). Of a total of 30 competitors contacted via telephone, 21 showed interest. They were then visited by an investigator to explain the protocol, inclusion and exclusion criteria and perform the anthropometric evaluation. The participants were forwarded for dietetic evaluation, where 16 athletes completed this phase, however, 2 athletes did not comply with the prescribed diet and were excluded. All 12 athletes completed the 2 trials (HI-PRO and HI-CHO), but 2 blood samples failed in the 24-h post-trial. Therefore, the final sample was composed of 10 males $(38 \pm 9.6$ yrs.; wt.: $72.9 \pm 8.7 \mathrm{~kg}$; ht.: $178.3 \pm 5.6 \mathrm{~cm}$; BF: $13.1 \pm 5.1 \%)$ amateur XCO athletes $(4.3 \pm 1.8$ yrs. experience; $6.7 \pm 3.5$ competitions performed; $5.0 \pm 1.0 \mathrm{~h} / \mathrm{wk}$. training). All were previously evaluated (IPAQ) and classified as very active ${ }^{22}$. The aims and risks were informed to the participants and they signed the Informed Consent Form. The inclusion criteria were: a) $\geq 18$ yrs.; b) $\geq 3 \mathrm{~h} / \mathrm{wk}$. training; c) $\geq 3$ years of experience in the $\mathrm{XCO}, \mathrm{d}) \geq 2$ competitions, while the following exclusion criteria were considered: a) incomplete trials and measures; b) all prescribed procedures were not followed; c) participant's wish to withdraw from the study.

\section{Pre-experimental procedures}

Anamnesis, anthropometric and nutritional evaluations were performed before the 1 st trial. The anthropometrical measures were performed by an expert evaluator according to the International Society for the Advancement of Kinanthropometry standard $^{23}$. Body mass was measured with an accuracy of $100 \mathrm{~g}$ (Filizola ${ }^{\circledR}$ Scale, SP, Brazil). Height was measured with $0.1 \mathrm{~cm}$ accuracy (stadiometer Sanny ${ }^{\circledR}$, SP, Brazil). Body density was indirectly estimated using the seven skinfolds equation for men ${ }^{24}$. Body fat percentage (BF) was estimated by the Siri ${ }^{25}$ equation.

All participants responded to the IPAQ questionnaire (short version) and completed a three-day food recall. Based on food preferences, each subject received a personalized diet from a nutritionist to meet the daily energy expenditure of the Estimated Energy Requirement (EER), which was calculated based on Dietary Reference Intakes (DRI) for energy ${ }^{26}$. To do so, we used the following equation for men above 19 years (EER $=662-9.53 \mathrm{x}$ age [yrs.] + physical activity $\mathrm{x}(15.91 \mathrm{x}$ body mass $[\mathrm{kg}]+539.6 \mathrm{x}$ height $[\mathrm{m}])$. In addition to the calories, the nutritional recommendations also considered an adequate intake of some such as iron, vitamin C, vitamin A, niacin, thiamine and riboflavin, calculated based on the $\mathrm{DRI}^{26,27}$, with the estimated intake of each nutrient being considered as the best estimate point (EAR). Adequate Intake (AI) was used 
for fiber and calcium. The recommended cut-off point was implemented for cholesterol consumption ${ }^{28}$. The diets were calculated using the Diet-Pro version 4.0 program configured for the Food Chemistry Composition Chart of the Brazilian Institute of Geography and Statistics. The calculated diet was prescribed and performed for four days (two before the 1st trial, at the trial and one day after, and this procedure was repeated for the $2^{\text {nd }}$ trial). In the trial, $1000 \mathrm{kcal}$ of the diet was replaced by test supplements (HI-PRO or HI-CHO). The athletes filled out the dietary recall throughout the data collection period, and these data were used as a control variable to avoid possible dietary bias interfering in the results. Those who presented food intake $10 \%$ above or below the prescribed were excluded from the final sample.

\section{Muscle damage, white and red blood cells}

Muscle damage was estimated by serum CPK and LDH levels, and the immune response by total and leukocytes fraction (neutrophils, lymphocytes, monocytes, basophils, eosinophils). Haemoglobin was measured and monitored as an indicator of aerobic performance ${ }^{29}$. Blood samples were collected to perform these measurements before (30-min), immediately after (30-min), and 24 hours after each trial. The blood (4-mL) was collected from the antecubital fossa vein, of which $2-\mathrm{mL}$ were deposited in tubes containing coagulant gel (Vacuette ${ }^{\circledR}$, Greiner Bio-one, Campinas, SP, Brazil). These samples remained at rest for 30-min at room temperature for coagulation and then centrifuged for 8-min at $2500 \mathrm{rpm}$ for serum separation. The remaining $(2-\mathrm{mL})$ was deposited in a tube containing $\mathrm{K}^{3}$-EDTA (Vacuette ${ }^{\circledR}$, Greiner Bio-one, Campinas, SP, Brazil) and centrifuged immediately for $10-\mathrm{min}$ at $3400 \mathrm{rpm}$ for plasma separation. Measures of CPK, LDH, white and red blood cells and haematocrit were performed on an automatic analyzer by dry chemical methodology (Vitros ${ }^{\circledR} 5600$, Ortho-Clinical Diagnostics, Johnson \& Johnson Company, Rochester, NY, USA). Blood collection was performed to the required standards by a laboratory-trained technician.

\section{Perceived pain and recovery}

The perceived pain and recovery were estimated through the visual analog scale, which is characterized by a $10-\mathrm{cm}$ horizontal scale. For pain, $0=$ the absence of pain, 1 to $3=$ low-intensity pain, 4 to $6=$ moderate intensity pain, 7 to $9=$ severe intensity pain, and $10=$ intolerable pain intensity, according to the methodology described by Hawker, Mian, Kendzerska and French 30 . For recovery, $0=$ no recovery, $1=$ very little recovery, $2=$ little recovery, $3=$ moderate recovery, $4=$ good recovery, $5=$ very good recovery, $7=$ very, very good recovery, $10=$ fully recovered, in agreement with the methodology described by Laurent et al. ${ }^{31}$. These perceived measures were performed before (30 $\mathrm{min})$, immediately after $(30 \mathrm{~min})$, and 24 hours after each trial.

\section{Supplementation protocol}

Two shakes were elaborated for the supplementation protocol: a) HI-PRO (70\% protein and 30\% carbohydrate); and b) $\mathrm{HI}-\mathrm{CHO}$ ( $70 \%$ carbohydrate and $30 \%$ protein). Hydrolysed whey-protein $\left(\right.$ Hydrowhey ${ }^{\circledR}$, Optimum Nutrition, USA) and maltodextrin (Mega MaltoDextrin ${ }^{\circledR}$, Probiotica, Brazil) were used to prepare the shakes. The HI-PRO was composed of $114 \mathrm{~g}$ of Hydrowhey ${ }^{\circledR}$ and $33 \mathrm{~g}$ of Mega MaltoDextrin ${ }^{\circledR}$. The HI-CHO shake was composed of $49 \mathrm{~g}$ of Hydrowhey ${ }^{\circledR}$ and $89 \mathrm{~g}$ of Mega MaltoDextrin $^{\circledR}$. Both were diluted in $500 \mathrm{~mL}$ of water, and the proportions of each supplement were calculated considering the information of the product labels, in which 39 grams of Hydrowhey ${ }^{\circledR}$ in its composition has 30 grams of PRO, 1 of lipids and 2 of $\mathrm{CHO}$, while the Mega MaltoDextrin ${ }^{\circledR}$ has 38 grams of $\mathrm{CHO}$ for every 40 grams. Both shakes had approximately $500 \mathrm{Kcal}$ and were ingested immediately and three hours after the test. The solutions were previously prepared in sealed bottles, presented the same texture, flavour and were presented in bottles that did not allow for identifying the colour. The control of this protocol was carried out by an investigator who had no contact with the athletes.

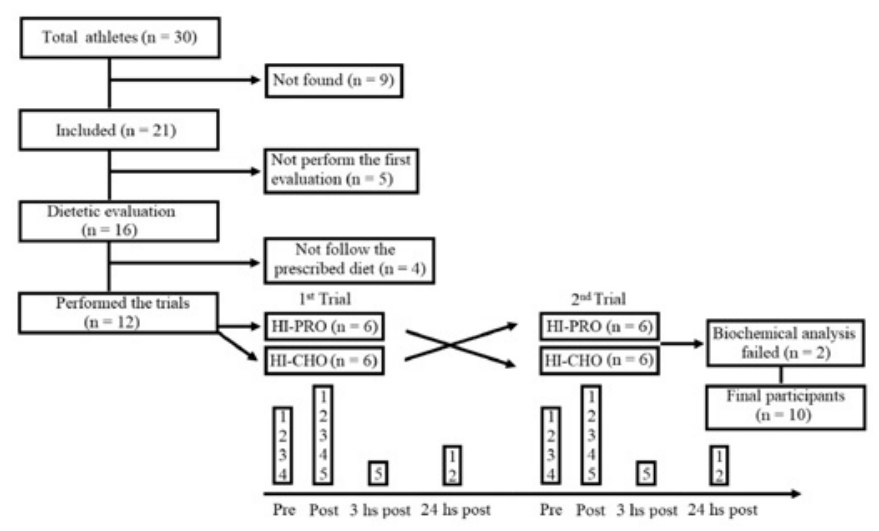

Figure 1. Chart and time line of experimental procedures. 1. Blood sample, 2. Perceived pain and recuperation, 3. Perceived exertion, 4. Heart rate and, 5. Supplementation.

\section{Statistical analysis}

An exploratory data analysis was initially performed to identify and correct extreme values. The normality of the data was verified by the Kolmogorov-Smirnov test and by the homoscedasticity test (Bartlett's criterion). When the presence of outliers was detected, the extreme values were replaced by the mean, and the logarithmic transformation of the variable was performed when the outliers exceeded 20\%. Two-way ANOVA (condition X measurement moment) with Bonferroni post-hoc was applied to establish the difference between means. We used the Mauchly sphericity test for validating the repeated measurements, and the GreenhouseGeisser correction was applied when necessary. The $t$-test for independent samples was used to verify the difference between the total trial time. Eta-squared $\left(\eta^{2}\right)$ and Cohen's d statistic were used to estimate the magnitude of the effects of treatments between 
groups. Lastly, ${ }^{\mathrm{p}}<0.05$ was used as the significance level in all analyses (SPSS, 20.0).

\section{Results}

Of the total measures $(n=240), 6.3 \%(n=15)$ were outliers, and no variable had outliers higher than $20 \%$. Regarding the measures performance, there was a significant difference between the moments of measurement for $\operatorname{HR}\left(\mathrm{F}_{1,38}=315.9 ; p \leq 0.001\right.$; $\eta^{2}=0.946$; Pre: $101.8 \pm 19.3$ and $103.7 \pm 21.2$ bpm; Post: $176.5 \pm 6.1$ and $174.1 \pm 8.5$ for HI-PRO and HI-CHO respectively) and RPE $\left(\mathrm{F}_{1,38}=2160.3 ; p \leq 0.001 ; \eta^{2}=0.992\right.$; Pre: $0 \pm 0$ and $0 \pm 0$ a.u.; Post: $9.1 \pm 0.9$ and $9.1 \pm 0.9$ for HI-PRO and HI-CHO, respectively), where the post-means were statistically higher compared to the pre-trial. However, there was no difference between conditions for these variables ( $p \geq 0.05$ ), or for the total trial time $\left(\mathrm{T}_{1,18}=0.309 ; p=0.76 ; \mathrm{d}=0.14: 96.6 \pm 10.4\right.$ vs. $\left.95.4 \pm 6.5 \mathrm{~min}\right)$. For $\mathrm{HI}-\mathrm{PRO}$ and $\mathrm{HI}-\mathrm{CHO}$, respectively, the cumulative altimetry $(1.038 .1 \pm 156.3 \mathrm{~m})$ was the same for both conditions. The temperature in the 1 st trial was $24.5 \pm 0.5^{\circ} \mathrm{C}$ and humidity $55 \pm 2 \%$, and in the $2^{\text {nd }}$ trial the temperature was $25 \pm 1.0{ }^{\circ} \mathrm{C}$ and humidity was $53 \pm 4 \%$. Table 1 presents the results for white, red blood cells and haematocrit concentration in HI-PRO and HI-CHO conditions.

Table 1. White blood cells, haemoglobin and haematocrit concentration at the pre-, post- and 24h-post-trial in HI-PRO and HI-CHO conditions.

\begin{tabular}{lccc}
\hline Marker. Mean \pm SD & Pre-trial & Post-trial & 24h-post-trial \\
\hline Leukocytes. cells X 10 & & & \\
HI-PRO & $7.7 \pm 1.8$ & $14.7 \pm 6.1^{\mathrm{a}}$ & $6.9 \pm 1.4$ \\
HI-CHO & $7.8 \pm 2.0$ & $13.6 \pm 5.6^{\mathrm{a}}$ & $7.1 \pm 1.4$ \\
Neutrophils. cells X $10^{3}$ & & & \\
HI-PRO & $4.4 \pm 1.5^{\mathrm{b}}$ & $11.9 \pm 5.2^{\mathrm{a}}$ & $3.6 \pm 1.2$ \\
HI-CHO & $4.4 \pm 1.8^{\mathrm{b}}$ & $10.7 \pm 4.9^{\mathrm{a}}$ & $3.9 \pm 1.1$ \\
Lymphocytes. cells X 10 & & & \\
HI-PRO & $2.5 \pm 0.8$ & $1.8 \pm 0.5^{\mathrm{a}}$ & $2.5 \pm 0.4$ \\
HI-CHO & $2.6 \pm 0.5$ & $2.0 \pm 0.6^{\mathrm{a}}$ & $2.4 \pm 0.6$ \\
Monocytes. cells X 10 & & & \\
HI-PRO & $0.5 \pm 0.2$ & $0.3 \pm 0.1^{\mathrm{a}}$ & $0.6 \pm 0.1$ \\
HI-CHO & $0.5 \pm 0.1$ & $0.4 \pm 0.2^{\mathrm{a}}$ & $0.6 \pm 0.1$ \\
Basophils. cells X 10 & & & \\
HI-PRO & $0.1 \pm 0.1$ & $0.4 \pm 0.2^{\mathrm{a}}$ & $0.1 \pm 0.1$ \\
HI-CHO & $0.1 \pm 0.1$ & $0.4 \pm 0.4^{\mathrm{a}}$ & $0.1 \pm 0.1$ \\
Eosinophils. cells X 10 & & & \\
HI-PRO & $0.2 \pm 0.2$ & $0.2 \pm 0.2$ & $0.2 \pm 0.2$ \\
HI-CHO & $0.2 \pm 0.2$ & $0.2 \pm 0.1$ & $0.2 \pm 0.1$ \\
Haemoglobin. (g/dL) & & & \\
HI-PRO & $14.8 \pm 0.7$ & $15.0 \pm 0.6$ & $14.8 \pm 0.7$ \\
HI-CHO & $14.8 \pm 0.9$ & $15.1 \pm 0.6$ & $14.8 \pm 0.8$ \\
Haematocrit. \% & & & \\
HI-PRO & $43.0 \pm 1.8$ & $43.8 \pm 1.4$ & $43.3 \pm 2.0$ \\
HI-CHO & $44.0 \pm 1.7$ & $43.8 \pm 1.9$ & $44.6 \pm 1.6$ \\
\hline
\end{tabular}

HI-PRO - high protein, HI-CHO - high carbohydrate, SD -

Standard deviation. ${ }^{\mathrm{a}} p \leq 0.043$ for this moment of measurement vs. The others, ${ }^{b} p=0.033$ for this moment of measurement vs. $24-\mathrm{h}$.
For the leukocytes, there was only an effect for the measurement moment $\left(\mathrm{F}_{1,38}=24.785 ; p \leq 0.001 ; \eta^{2}=0.745\right)$, where means obtained post-trial differed significantly from pre-trial $(p \leq 0.001 ; 95 \%$ CI $3.3 ; 9.6)$ and $24-\mathrm{h}$ after trials $(p \leq 0.001,95 \% \mathrm{CI} 4.2,10.2)$. For the neutrophils, there was an effect of the measurement moment $\left(\mathrm{F}_{1,38}=42.649 ; p \leq 0.001\right.$; $\left.\eta^{2}=0.834\right)$, where post-trial means differed significantly from the pre-trial $(p \leq 0.001 ; 95 \%$ CI $4.0 ; 9.8)$ and 24 -h post-trial $(p \leq 0.001,95 \% \mathrm{CI} 4.9,10.2)$, and the pre-trial differed from the 24 -h post-trial $(p=0.033,95 \%$ CI $0.1 ; 1.3)$. An isolated difference for the moment measurement were also observed for the lymphocytes $\left(\mathrm{F}_{1,38}=14.309 ; p \leq 0.001 ; \eta^{2}=0.627\right)$, where post-trial means differed significantly from the pre-trial $(p \leq 0.001 ; 95 \% \mathrm{CI}-0.9 ;-0.3)$ and $24-\mathrm{h}$ post trials $(p=0.001$; $95 \%$ CI $-0.9 ;-0.2)$. A similar result was observed for the monocytes $\left(\mathrm{F}_{1,38}=14.309 ; p \leq 0.001 ; \eta^{2}=0.627\right)$, where the post-trial differed significantly from the pre-trial means $(p=0.043 ; 95 \% \mathrm{CI}-0.3 ;-0.01)$ and $24-\mathrm{h}$ post-trials $(\mathrm{p} \leq 0.001$; $95 \% \mathrm{CI}-0.3 ;-0.1)$. For the basophils, there was an isolated effect of the measurement moment $\left(\mathrm{F}_{1,38}=13.485 ; p \leq 0.001\right.$; $\left.\eta^{2}=0.613\right)$, the means observed post-trials differed statistically from the pre-trial $(p \leq 0.001,95 \% \mathrm{CI} 0.2)$ and 24 -h post-trial $(p \leq 0.001 ; 95 \%$ CI $0.2 ; 0.5)$. For eosinophils, there was no significant effect $\left(\mathrm{F}_{1,38}=0.489, p=0.622, \eta^{2}=0.054\right)$. A similar result was observed for haemoglobin $\left(\mathrm{F}_{1,38}=3,204, p=0.066\right.$, $\left.\eta^{2}=0.274\right)$ and the haematocrit concentration $\left(F_{1,38}=3.214\right.$, $p=0.052, \eta^{2}=0.151$ ).
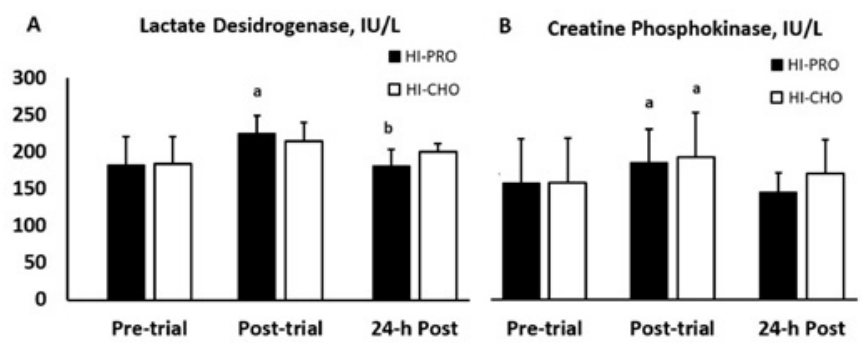

Figure 2. Serum Lactate Desidrogenase (A) and Creatine Phosphokinase (B) at pre-, post- and 24h-post-trial in high protein (HI-PRO) and high carbohydrate (HI-CHO) conditions. ap $\leq 0.026$ for this moment measurement vs. the others, $b p=0.019$ vs. HI-CHO condition.

For estimated muscle damage, there was an interaction effect for $\operatorname{LDH}\left(\mathrm{F}_{1,38}=3.947, p=0.039, \eta^{2}=0.317\right)$ for the HI-PRO, as the mean observed at post-trial differed from pre-trial $(p=0.019,95 \%$ CI $22.1,66.3)$ and 24 -h post-trial $(p=0.019$, $95 \% \mathrm{CI}-35.8 ;-3.6)$, while the means observed $24-\mathrm{h}$ post-trial were statistically lower for the HI-PRO $(p=0.019 ; 95 \% \mathrm{CI}$ $-35.8 ;-3.6)$ in comparison to HI-CHO. For the CPK, there was an isolated effect of the measurement moment $\left(\mathrm{F}_{1,38}=11.477\right.$, $\left.p=0.001, \eta^{2}=0.575\right)$, where the means observed post-trial differed statistically from the pre-trial ( $p=0.026,95 \%$ CI 3.5 , 64.0 ) and $24-\mathrm{h}$ post-trial ( $p=0.001,95 \%$ CI $14.1 ; 51.9)$. Table 2 presents the results for perceived pain and perception of recovery. 
Table 2. Perceived pain and perception of recovery at pre-, post- and 24h-post-trial in HI-PRO and HI-CHO conditions.

\begin{tabular}{lccc}
\hline Marker, Mean \pm SD & Pre-trial & Post-trial & 24h-post-trial \\
\hline Perceived pain, a.u. & & & \\
HI-PRO & $2.3 \pm 2.5$ & $6.6 \pm 2.4^{\mathrm{a}}$ & $1.6 \pm 1.0$ \\
HI-CHO & $2.5 \pm 2.4$ & $4.2 \pm 1.7^{\mathrm{a}}$ & $0.8 \pm 0.9$ \\
Perception of recovery, a.u. & & \\
HI-PRO & $7.1 \pm 2.0$ & $2.6 \pm 1.3^{\mathrm{a}}$ & $7.3 \pm 1.8$ \\
HI-CHO & $7,1 \pm 2.1$ & $3.6 \pm 1.8^{\mathrm{a}}$ & $6.8 \pm 2.7$ \\
\hline
\end{tabular}

HI-PRO - high protein, HI-CHO - high carbohydrate, SD Standard deviation, a.u - arbitrary units, ${ }^{\mathrm{a}} p \leq 0.002$ for this moment measurement vs. the others.

Regarding the perceived pain, there was an isolated effect for the moment measurement $\left(\mathrm{F}_{1,38}=34.411, p=0.001, \eta^{2}=0.802\right)$, where the means observed at the post-differed from the pre- $(p=0.002,95 \% \mathrm{CI}-5.1 ;-1.1)$ and 24 -h post-trial $(p \leq 0.001$; $95 \% \mathrm{CI} 2.9 ; 5.5)$. For the perception of recovery, there was also an isolated effect of the moment measurement $\left(\mathrm{F}_{1,38}=26.454\right.$; $\left.p \leq 0.001 ; \eta^{2}=0.757\right)$, where the mean observed at post-trial statistically different from the pre-trial $(p \leq 0.001,95 \% \mathrm{CI}-5.7$; $-2-3)$ and 24 -h post-trial $(p \leq 0.001 ; 95 \%$ CI $5.6 ;-2-3)$.

\section{Discussion}

In applying a cross-sectional randomized double-blind crossover trial, this study aimed to investigate the influence of HIPRO and HI-CHO supplementation on muscle damage, immune response and perceived pain, and perception of recovery after simulated XCO. The main results indicated that HI-PRO intake induced lower muscle damage (LDH) 24-h post-trial. Protein plus carbohydrates supplements are consumed by athletes and physical activity practitioners to increase performance and accelerate recovery, but this decision is primarily based on marketing and advertising rather than scientific evidence ${ }^{32}$. According to ${ }^{33}$, investigations up to the last decade with post-exercise nutrition aimed to replace water, electrolytes and carbohydrates; but starting from 2001, study protocols that investigated the postexercise effect of $\mathrm{CHO}$ and PRO on recovery began.

In a meta-analysis review, McLellan, Pasiakos and Lieberman $^{32}$ analysed 28 well-conducted studies on this theme; however, there is a limitation as to the interpretation of the results since there was no isocaloric comparison of the supplements in most protocols. Among these, Williams, Raven, Fogt and Ivy ${ }^{33}$ observed that a sports drink $(355 \mathrm{~mL})$ containing $\mathrm{CHO}$ $(0.8 \mathrm{~g} / \mathrm{kg} \mathrm{BW})$ and PRO $(0.2 \mathrm{~g} / \mathrm{kg} \mathrm{BW})$ increased the time to fatigue in a subsequent cycling test, in addition to inducing a higher glycogen restoration when compared to only $\mathrm{CHO}$ $(0.3 \mathrm{~g} / \mathrm{kg} \mathrm{BW})$. Two studies compared isocaloric amounts of CHO-PRO vs. CHO. In runners, Niles, et al. ${ }^{34}$ was the first to observe the higher ergogenic effect of post-exercise CHO-PRO intake on subsequent performance. Similar results were observed in another study with runners, where Millard-Stafford, Warren, Thomas, Doyle, Snow and Hitchcock ${ }^{35}$ also observed an increased performance of CHO-PRO and lower perceived pain. To the best of our knowledge, the present study protocol was the first to compare mixed isocaloric sports drinks containing CHO-PRO.

A challenge for conducting cross-over studies with simulated field tests is to be able to repeat the experimental conditions. However, the performance measures indicated that the effort required was similar since there was no difference between the total trial time, heart rate, RPE, and accumulated altimetry. In addition, the haematocrit concentration showed that the performed hydration was also similar. Hydration monitoring is fundamental for interpreting the results since dehydration can affect the immune response of athletes ${ }^{15,36}$.

To the best of our knowledge, no studies have investigated the effect of CHO-PRO supplementation on the immune response in XCO athletes. However, our results show the importance of monitoring the immune response in this sport, since we observed leucocytosis (concentration $\geq 11.0 \mathrm{X}$ $10^{3}$ cells) and neutrophils (concentration $\geq 7.5 \times 10^{3}$ cells) after the trials $\mathrm{s}^{37}$. The present result showed a strong effect size on the effect of increasing neutrophil and leucocytosis levels during post-training, inducing immunosuppression ${ }^{36}$. In fact, changes in neutrophil concentrations are a concern, since these cells are the first line of defense against infections ${ }^{37}$. However, Moreira, Delgado, Moreira and Haahtela ${ }^{38}$ state that there is a lack of stronger evidence to associate transient immunosuppression with the development of infections in athletes, especially those associated with the upper respiratory tract.

Regarding the effect of CHO-PRO intake on the immune response, Venkatraman and Pendergas $\mathrm{t}^{15}$ state that adequate amounts are essential for maintaining immune function in athletes and to avoid overtraining. However, little has been studied about CHO-PRO intake after exercise and immune modulation. Venkatraman and Pendergast ${ }^{15}$ observed that $1.2 \mathrm{~g} / \mathrm{kg}$ BW did not affect the leukocyte concentration but prevented the degranulation of neutrophils. In our study, the approximate amount of CHO was 0.5 , and $1.2 \mathrm{~g} / \mathrm{kg} \mathrm{BW}$ for HI-PRO and $\mathrm{HI}-\mathrm{CHO}$; respectively. It is also emphasized that there was also a significant decrease with a strong effect size on the concentration of monocytes and lymphocytes but without relevant clinical implications. More studies are needed to verify the importance of post-exercise CHO-PRO supplementation and its immune modulator effects ${ }^{39}$.

One of the factors that increase the leukocyte concentration post-intense effort is the muscle damage resulting from exertion ${ }^{39}$. Increased serum CPK and LDH has been associated with a lower capacity of the muscle strength ${ }^{5,11,40}$. Like the present protocol, other studies have investigated the effect of post-exercise supplementation in muscle damage. Rustad, et al. ${ }^{41}$ did not observe a difference in muscle damage (CPK and LDH) 18 hours after a maximal cycling test when athletes consumed carbohydrate $(1.2 \mathrm{~g} / \mathrm{kg} \mathrm{BW})$ or CHO-PRO $(0.8+0.4 \mathrm{~g} / \mathrm{kg} \mathrm{BW})$, but CHO-PRO resulted in positive nitrogen balance and better performance after the recovery. There is still no clarity about the recuperative effect of $\mathrm{CHO}$ and $\mathrm{PRO}$ on muscle damage enzymes; Brown, Stevenson and Howatson ${ }^{42}$ found that the intake of whey protein $(20 \mathrm{~g})$ compared to $\mathrm{CHO}(21.8 \mathrm{~g})$ resulted in a lower concentration of CPK 48-hours after sprinting (15 X $30 \mathrm{~m})$. Also, Cooke, Rybalka, Stathis, Cribb and Hayes ${ }^{5}$ did not observe 
differences in CPK and LDH concentrations when consuming whey protein $(1.5 \mathrm{~g} / \mathrm{kg} . \mathrm{BW} /$ day $)$ or $\mathrm{CHO}(1.5 \mathrm{~g} / \mathrm{kg} . \mathrm{BW} /$ day $)$ after eccentric training but it was noted that the study was performed in sedentary subjects. The wide diversity of methodologies and populations investigated possibly contribute to the different results found in measuring these enzymes ${ }^{40}$. Cooke, Rybalka, Stathis, Cribb and Hayes ${ }^{5}$ state that serum CPK, in general, is due to muscle damage, and the lower concentration of this enzyme is an indicator of muscle recovery, but it must be recognized that there is higher inter- and intra-subject variability.

The perceived pain and perception of recovery were two other indicators that showed the high degree of physical demand of the trial. However, the recovery course was similar for both conditions. Pasiakos, Lieberman and McLellan ${ }^{14}$ report that there are a limited number of well-conducted experimental studies demonstrating that CHO-PRO intake before or after exercise attenuates the muscle soreness (Evidence category B). Even though haemoglobin and haematocrit concentrations showed acute variations associated with high-intensity exercise ${ }^{29}$, there was no significant change in these blood measures over the experimental period. These changes usually occur when athletes do not adequately rehydrate during exercise ${ }^{43}$. Wirnitzer and Faulhaber ${ }^{29}$ observed changes in haematocrit and haemoglobin concentrations throughout an eight-day mountain biking competition where athletes did not rehydrate appropriately.

Among all the measures, only one (LDH) showed a difference compared to the two conditions. There seem to be few advantages to the HI-PRO; on the other hand, according to our estimates, each dose would represent 3-times higher cost for an athlete in comparison to HI-CHO. We recommend that athletes and coaches evaluate the cost-effectiveness of the diet before making their choices. We also emphasize that the present experimental design focused on the intake of supplements in the post-trial, as a higher rate of absorption of nutrients occurs during this period $^{19}$. However, future studies may investigate whether intake times will modify the effects. Compared to placebo, Cathcart, Murgatroyd, McNab, Whyte and Easton ${ }^{3}$ verified a better performance in mountain biking cyclists who consume a shake ( $20 \% \mathrm{CHO}-80 \% \mathrm{PRO})$. We emphasize that the results of the present study focus on the analysis of biochemical and subjective measures; the evaluation of the physical performance after recovery can increase understanding about the recovery effect of CHO-PRO. Based on our objectives, applied procedures, results, and limitations, we conclude that HI-PRO supplementation results in better muscle damage (LDH) recovery, but only for $\mathrm{LDH}$, after XCO simulated competition. Athletes and coaches should evaluate the cost-benefit of taking the supplementation immediately post-training or competition.

\section{References}

1. Burr JF, Drury CT, Ivey AC, Warburton DE. Physiological demands of downhill mountain biking. J Sports Sci. 2012; 30(16):1777-85.

2. Macdermid PW, Stannard S. Mechanical work and physiological responses to simulated cross country mountain bike racing. J Sports Sci. 2012; 30(14):1491-501.
3. Cathcart AJ, Murgatroyd SR, McNab A, Whyte LJ, Easton C. Combined carbohydrate-protein supplementation improves competitive endurance exercise performance in the heat. Eur J Appl Physiol. 2011; 111(9):2051-61.

4. Belli T, Macedo DV, De Araujo GG, dos Reis IGM, Scariot PPM, Lazarim FL, et al. Mountain Ultramarathon Induces Early Increases of Muscle Damage, Inflammation, and Risk for Acute Renal Injury. Frontiers in Physiology. 2018; 9.

5. Cooke MB, Rybalka E, Stathis CG, Cribb PJ, Hayes A. Whey protein isolate attenuates strength decline after eccentrically-induced muscle damage in healthy individuals. J Int Soc Sports Nutr. 2010; 7(1):1-9.

6. Stellingwerff T, Bovim IM, Whitfield J. Contemporary Nutrition Interventions to Optimize Performance in Middle-Distance Runners. International journal of sport nutrition and exercise metabolism. 2018:1-29.

7. Matsumoto K, Koba T, Hamada K, Sakurai M, Higuchi T, Miyata H. Branched-chain amino acid supplementation attenuates muscle soreness, muscle damage and inflammation during an intensive training program. J Sports Med Phys Fitness. 2009; 49:4.

8. Cooke MB, Rybalka E, Williams AD, Cribb PJ, Hayes A. Creatine supplementation enhances muscle force recovery after eccentrically-induced muscle damage in healthy individuals. J Int Soc Sports Nutr. 2009; 6(1):1-11.

9. Ra S, Miyazaki T, Kojima R, Komine S, Ishikura K, Kawanaka K, et al. Effect of BCAA supplement timing on exercise-induced muscle soreness and damage: a pilot placebo-controlled double-blind study. The Journal of sports medicine and physical fitness. 2017.

10. Rubio-Arias JÁ, Ávila-Gandía V, López-Román FJ, Soto-Méndez F, Alcaraz PE, Ramos-Campo DJ. Muscle damage and inflammation biomarkers after two ultra-endurance mountain races of different distances: $54 \mathrm{~km}$ vs $111 \mathrm{~km}$. Physiology \& behavior. 2018 .

11. Kim HJ, Lee YH, Kim CK. Biomarkers of muscle and cartilage damage and inflammation during a $200 \mathrm{~km}$ run. Eur J Appl Physiol. 2007; 99(4):443-7.

12. Skurvydas A, Brazaitis M, Venckunas T, Kamandulis S. Predictive value of strength loss as an indicator of muscle damage across multiple drop jumps. Appl Physiol Nutr Metab. 2011; 36(3):353-60.

13. Thompson D, Bailey D, Hill J, Hurst T, Powell J, Williams C. Prolonged vitamin $\mathrm{C}$ supplementation and recovery from eccentric exercise. Eur J Appl Physiol. 2004; 92(1):133-8.

14. Pasiakos SM, Lieberman HR, McLellan TM. Effects of protein supplements on muscle damage, soreness and recovery of muscle function and physical performance: a systematic review. Sports Med. 2014; 44(5):655-70.

15. Venkatraman JT, Pendergast DR. Effect of dietary intake on immune function in athletes. Sports Med. 2002; 32(5):323-37.

16. Hansen M, Bangsbo J, Jensen J, Bibby BM, Madsen K. Effect of whey protein hydrolysate on performance and recovery of topclass orienteering runners. Int J Sport Nutr Exerc Metab. 2015; 25(2):97-109.

17. Flakoll PJ, Judy T, Flinn K, Carr C, Flinn S. Postexercise protein supplementation improves health and muscle soreness during basic military training in Marine recruits. J Appl Physiol. 2004; 96(3):951-6.

18. Ortega F, Ruiz J, Gutierrez A, Castillo M. Extreme mountain bike challenges may induce sub-clinical myocardial damage. J Sports Med Phys Fitness. 2006; 46(3):489-93. 
19. Aragon AA, Schoenfeld BJ. Nutrient timing revisited: is there a post-exercise anabolic window? J Int Soc Sports Nutr. 2013; 10(1):5.

20. Costa V, De-Oliveira F. Physiological variables to predict performance in cross-country mountain bike races. J Exerc Physiol. 2008; 11:14-24.

21. Borg GA. Psychophysical bases of perceived exertion. Med Sci Sports Exerc. 1982; 14(5):377-81.

22. Craig CL, Marshall AL, Sjöström M, Bauman AE, Booth ML, Ainsworth BE, et al. International physical activity questionnaire: 12-country reliability and validity. Med Sci Sports Exerc. 2003; 35(8):1381-95.

23. Marfell-Jones M, Olds TS, Stewart A, Carter L. International standards for anthropometric assessment (ISAK). South Africa: Potchefstroom; 2006.

24. Jackson AS, Pollock ML. Generalized equations for predicting body density of men. Br J Nutr. 1978; 40(3):497-504.

25. Siri WE. Body composition from fluid spaces and density: analysis of methods. 1961. Nutrition. 1993; 9(5):480-91.

26. Medicine Io. Energy. In: Medicine Io, editor. Dietary Reference Intakes for Energy, Carbohydrate, Fiber, Fat, Fatty Acids, Cholesterol, Protein, and Amino Acids. 1. Washington DC: The National Academy Press; 2005. p. 107-264.

27. Medicine Io. Dietary Reference Intakes for Vitamin C, Vitamin E, Selenium, and Carotenoids. Washington DC: The National Academies Press; 2000. 529 p.

28. Medicine Io. Cholesterol. In: Medicine Io, editor. Dietary Reference Intakes for Energy, Carbohydrate, Fiber, Fat, Fatty Acids, Cholesterol, Protein, and Amino Acids. 1. Washington DC: The National Academy Press; 2005. p. 542-88.

29. Wirnitzer KC, Faulhaber M. Hemoglobin and hematocrit during an 8 day mountainbike race: A field study. J Sports Sci Med. 2007; 6(2):265.

30. Hawker GA, Mian S, Kendzerska T, French M. Measures of adult pain: Visual analog scale for pain (vas pain), numeric rating scale for pain (nrs pain), mcgill pain questionnaire (mpq), short-form mcgill pain questionnaire (sf-mpq), chronic pain grade scale (cpgs), short form-36 bodily pain scale (sf-36 bps), and measure of intermittent and constant osteoarthritis pain (icoap). Arthritis Care Res. 2011; 63(S11).

31. Laurent CM, Green JM, Bishop PA, Sjökvist J, Schumacker RE, Richardson MT, et al. A practical approach to monitoring recovery: development of a perceived recovery status scale. J Strength Cond Res. 2011; 25(3):620-8.

32. McLellan TM, Pasiakos SM, Lieberman HR. Effects of protein in combination with carbohydrate supplements on acute or repeat endurance exercise performance: a systematic review. Sports Med. 2014; 44(4):535-50.

33. Williams MB, Raven PB, Fogt DL, Ivy JL. Effects of recovery beverages on glycogen restoration and endurance exercise performance. J Strength Cond Res. 2003; 17(1):12-9.

34. Niles ES, Lachowetz T, Garfi J, Sullivan W, Smith JC, Leyh BP, et al. Carbohydrate-protein drink improves time to exhaustion after recovery from endurance exercise. J Exerc Physiol. 2001; $4(1): 45-52$.
35. Millard-Stafford M, Warren GL, Thomas LM, Doyle JA, Snow T, Hitchcock K. Recovery from run training: efficacy of a carbohydrate-protein beverage? Int J Sport Nutr Exerc Metab. 2005; 15(6):610-24.

36. Walsh NP, Gleeson M, Shephard RJ, Gleeson M, Woods JA, Bishop N, et al. Position statement part one: immune function and exercise. Exerc Immunol Rev. 2011; 17:6-63.

37. Boxer L. Leukocytosis. Practical Algorithms in Pediatric Hematology and Oncology: Karger Publishers; 2003. p. 38-9.

38. Moreira A, Delgado L, Moreira P, Haahtela T. Does exercise increase the risk of upper respiratory tract infections? Br Med Bull. 2009; 90(1):111-31.

39. Cruzat VF, Krause M, Newsholme P. Amino acid supplementation and impact on immune function in the context of exercise. J Int Soc Sports Nutr. 2014; 11(1):61.

40. Bird SR, Linden M, Hawley JA. Acute changes to biomarkers as a consequence of prolonged strenuous running. Ann Clin Biochem. 2014; 51(2):137-50.

41. Rustad PI, Sailer M, Cumming KT, Jeppesen PB, Kolnes KJ, Sollie $\mathrm{O}$, et al. Intake of protein plus carbohydrate during the first two hours after exhaustive cycling improves performance the following day. PloS one. 2016; 11(4):e0153229.

42. Brown MA, Stevenson EJ, Howatson G. Whey protein hydrolysate supplementation accelerates recovery from exercise-induced muscle damage in females. App Physiol Nutr Metab. 2017:1-37.

43. Mounier R, Pialoux V, Mischler I, Coudert J, Fellmann N. Effect of hypervolemia on heart rate during 4 days of prolonged exercises. Int J Sport Med. 2003; 24(07):523-9.

\section{Acknowledgments}

The authors gratefully acknowledge the Scientific Initiation Program of Federal University of Juiz de Fora. The research was conducted in the LAFIM, laboratory of Physiological and motor analysis in health and performance of the Physical Education Department (Federal University of Juiz de Fora).

\section{Corresponding author}

Ciro José Brito

Departamento de Educação Física. Universidade Federal de Juiz de Fora.Rua José Lourenço Kelmer, S/n, Martelos, Juiz de Fora, MG, 36036-330

Email: cirojbrito@gmail.com

Manuscript received on October 9, 2018

Manuscript accepted on February 20, 2019

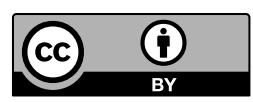

Motriz. The Journal of Physical Education. UNESP. Rio Claro, SP, Brazil - eISSN: 1980-6574 - under a license Creative Commons - Version 4.0 